\title{
Comparison of Mortality Risk Factors in Elderly and Young Pulmonary Embolism Patients
}

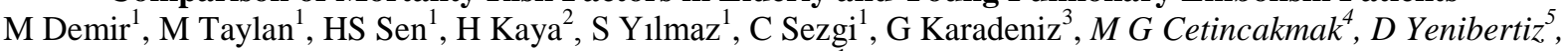
F Topcu ${ }^{1}$

\begin{abstract}
Objective: To determine clinical, radiological, and laboratory findings as well as mortality rates in younger and older patients with pulmonary embolism (PE) and investigate risk factors associated with mortality in elderly patients.
\end{abstract}

Materials and Methods: We have evaluated patients with acute PE. Characteristics of patients, presence of deep vein thrombosis, co-morbidities, other risk factors for PE, and mortality rates were recorded. Cases were categorized into elderly ( $\geq 65$ years old) and younger groups and their findings were compared.

Results: Number of PE patients were 253. 105 (41.5\%) of them were older and 148(58.5\%) were younger patients. Comparison of groups revealed more frequent presence of co-morbidities, higher simplified pulmonary embolism severity index (sPESI), and mortality rates in older group (All p values <0.001). Elderly cases also had higher right atrial diameters, pulmonary artery systolic pressure levels, and higher frequency of thrombi in proximal pulmonary arterial branches (p values: $0.015,0.001$, and 0.042 , respectively). Mortality rate was higher in elderly cases than the youngers [30 (28.6\%) vs. $19(12.8 \%), \mathrm{p}=0.002]$. Multivariate analysis revealed that a sPESI $\geq 1(p=0.034$, OR:5.25), increased C-reactive protein $(C R P)(p=0.004, O R: 1.26)$, and blood urea nitrogen $(\mathrm{BUN})(\mathrm{p}=0.019, \mathrm{OR}: 1.04)$ levels, having operation $(\mathrm{p}=0.049, \mathrm{OR}: 3.92)$, and presence of co-morbidities $(\mathrm{p}=$ 0.016, OR:6.21) were independent risk factors increasing mortality in elderly cases. As to youngers, increased BUN levels ( $\mathrm{p}=0.010$, OR: 1.09) and pulmonary infarction $(\mathrm{p}=0.125, \mathrm{OR}: 1.01)$ were independent risk factors.

Conclusions: We found high mortality rate in elderly PE patients and sPESI, presence of co-morbidities, surgery, high BUN and CRP levels can be used in prediction of mortality risk in those cases.

Keywords: Co-morbidities, elderly, mortality, pulmonary embolism, risk factors, young

From: ${ }^{1}$ Dicle University Faculty of Medicine, Department of Chest Disease, 21280 Diyarbakir, Turkey, ${ }^{2}$ Bursa Sevket Yilmaz Training and Research Hospital, Department of Chest Disease, 16310 Bursa, Turkey, ${ }^{3}$ Sifa University Faculty of Medicine, Department of Chest Disease, 35010 Izmir, Turkey, ${ }^{4}$ Dicle University Faculty of Medicine, Department of Radiology, 21280 Diyarbakir, Turkey, ${ }^{5}$ Dr Abdurrahman Yurtaslan Ankara Oncology Training and Research Hospital, Department of Chest Disease, 06020 Ankara, Turkey.

Correspondence: Dr M Demir, Department of Chest Disease, Faculty of Medicine, Dicle University 21280

Sur/Diyarbakir, Turkey. Fax: +90(412)248 82 40, E -mail: melikedoktor@ hotmail.com 


\section{INTRODUCTION}

Pulmonary embolism (PE) is a major health problem in elderly patients associated with significant morbidity and mortality. While the incidence of pulmonary embolism in general population is $0.5-1 / 1000(1)$, it increases with aging and reaches as high as 4/1000 in patients older than 70 years of age (2). The age-related increase in frequencies of deep vein thrombosis and PE may result from some changes observed in aging individuals including increment of fibrinogen, reduction of antithrombin-3, reduction of muscle mass in the extremities and venous stasis because of immobility(3).

The presence of accompanying co-morbidities and confusion of symptoms and signs of PE with those of co-morbidities in geriatric population lead to delays in diagnosis and treatment of PE (4). Furthermore, because of reduced cardio-pulmonary reserve in elderly patients, the ventilation/perfusion balance deteriorates more markedly after embolism compared to younger patients and emerging right heart failure results in mortality (5). The determination of risk factors associated with mortality in elderly PE patients may contribute to proper management of these cases. Although there are some previous reports evaluating such risk factors in various PE populations (6-10), small number of them have evaluated geriatric population (7-10). Moreover, studies comparing geriatric and non-geriatric patients are sparse $(9,10)$.

In the current study, we aimed to determine clinical, radiological, and laboratory findings as well as mortality rates in older patients with PE and to compare them with younger patients in terms of those findings. It was also aimed to investigate the risk factors associated with mortality and their predictive values in elderly PE patients. 


\section{MATERIALS AND METHODS}

\section{The characteristics of patients}

In this study, we have retrospectively evaluated the patients hospitalized with acute PE in Pulmonology Clinic of Dicle University Faculty of Medicine, between January 2010 and December 2014. Patients under 18 years of age and with inadequate clinical information were excluded from the study. The study was approved by local ethics committee.

\section{Study design}

The demographic and clinical characteristics of patients, co-morbid diseases, presence of deep vein thrombosis, recent operations, and other risk factors for PE and laboratory findings including complete blood count, blood biochemical parameters, arterial blood gas analysis, markers of hypercoagulable state, and the treatment applied were denoted from electronic database of the hospital and medical records of the patients. The blood samples had been obtained within 24 hours of admission. Computerized tomography pulmonary angiography and transthoracic echocardiography results were also recorded. All-cause mortality status within 90 days following PE diagnosis was searched and recorded for every patient using computerized database.

The severity of PE was assessed according to simplified pulmonary embolism severity index (SPESI) value which was calculated for every patient. For calculation of sPESI, one point was given for the presence of each of the following: age $>80$ years, history of cancer, history of chronic cardiopulmonary disease, heart rate $\geq 110$ beats/min, systolic blood pressure $<100 \mathrm{mmHg}$, and an arterial oxygen saturation $<90 \%$ at the time of PE diagnosis and accordingly, the patients were classified into low-risk ( 0 point) or high-risk ( $\geq 1$ point) categories (11). Massive PE was diagnosed according to the Guidelines on the Diagnosis And Management of Acute Pulmonary Embolism of the European Society of Cardiology(1) . 
The cases over 65 years of age were categorized into "older" group, while the remainder constituted the "younger" group. Then, the clinical and laboratory findings of these two groups were compared.

\section{The transthoracic echocardiographic evaluation}

All echocardiographic examinations were performed in accordance with the recommendations of the American Society for Echocardiography (11). A Vivid 7 Pro ultrasound system (GE Medical Systems, Vingmed Ultrasound AS, Norway) was used with appropriate transducers to carry out echocardiographic studies. Left and right ventricular as well as left and right atrial diameters, left ventricular shortening and ejection fractions, and pulmonary artery systolic pressure were measured and recorded. The patients with a pulmonary artery systolic pressure greater than $40 \mathrm{mmHg}$ was accepted to have pulmonary hypertension(12).

\section{Evaluation of computerized tomography (ct) pulmonary angiography}

Every patients underwent CT pulmonary angiography on a 64 slice multi detector CT scanner (Brilliance CT scanner, Philips Healthcare, Netherlands). The scanning was performed by application of $64 \times 0.625 \mathrm{~mm}$ collimation, $1 \mathrm{~mm}$ slice thickness, $0.5 \mathrm{~mm}$ reconstruction increment, and 0.5-second rotation time. One hundred milliliters of a nonionic contrast medium was applied by an automatic injector (CT Injector Missouri, Ulrich Medical, Germany) at a flow rate of $5 \mathrm{~mL} / \mathrm{s}$, followed by $30-40 \mathrm{~mL} \mathrm{NaCl}$ bolus via an antecubital vein. The diagnosis of PE was established by visualization of non-occlusive endoluminal thrombus or complete occlusion of pulmonary artery and/or its branches by thrombus (13).

\section{The statistical analysis}

Data analysis was performed using a statistical software package (SPSS 15.0; SPSS Inc, Chicago, IL). The Kolmogorov- Smirnov test was utilized to test distribution pattern of 
continuous variables. Data with normal distribution were shown as mean with standard deviation and qualitative variables were demonstrated as number and percentage. Parameters without such a distribution were identified as medians along with interquartile range value. Student t-test was used for the comparison of the two groups with normal distribution. Qualitative variables were compared by chi-square test. Parameters with significant differences were further evaluated with binary logistic regression analysis to determine independent risk factors for 90-day-mortality. Odds ratios (OR) with 95\% confidence intervals (CI) were calculated. Variables with a $p$ value less than 0.05 in univariate analysis were included in multivariate model.

\section{RESULTS}

Total number of PE patients were 253. One hundred and fifty-four of them $(60.9 \%)$ were female and the remainder $99(39.1 \%)$ were male (female/male: 1.6$)$. One hundred five $(41.5 \%)$ were older, while $148(58.5 \%)$ were younger patients. The mean age of older and younger cases were $75.5 \pm 6.4$ and $45.2 \pm 12.8$ years, respectively. Comparison of these groups revealed more frequent presence of co-morbidities and higher sPESI scores in older group. (Table 1). The 90-day mortality rate of older patients was higher than younger patients [30 (28.6\%) vs. $19(12.8 \%), \mathrm{p}=0.002)$. Presenting symptoms, PE-related risk factors, and the medications used in first-line and maintenance therapy did not differ between the groups.

The comparison of radiological and other laboratory findings of older and younger groups were shown in Table 2 . While mean lymphocyte counts $\left[(1.7 \pm 0.7) \times 10^{3} / \mu \mathrm{L}\right.$ vs. $\left.(1.9 \pm 1.0) \times 10^{3} / \mu \mathrm{L}, \mathrm{p}=0.002\right]$ and albumin levels $(2.6 \pm 0.5 \mathrm{~g} / \mathrm{dL}$ vs. $2.9 \pm 0.6 \mathrm{~g} / \mathrm{dL}, \mathrm{p}=0.001)$ were significantly lower, mean MPV values $(8.2 \pm 1.5 \mathrm{fL}$ vs. $7.8 \pm 1.4 \mathrm{fL}, \mathrm{p}=0.032)$ and serum 
blood urea nitrogen $(B U N)(23.3 \pm 13.3 \mathrm{mg} / \mathrm{dL}$ vs. $15.1 \pm 8.7 \mathrm{mg} / \mathrm{dL}, \mathrm{p}<0.001)$ were higher in elderly patients. Arterial blood gas analysis revealed lower partial oxygen pressure $(60.5 \pm 15.3$ mmHg vs. $68.8 \pm 13.2 \mathrm{mmHg}, \mathrm{p}=0.001)$ and median oxygen saturation levels [86.3(9.5) vs. $94(6), p=0.002]$ in elderly group. Higher D-dimer levels were found in elderly group compared to younger cases $(2331.5 \pm 1301.2 \mathrm{ng} / \mathrm{mL}$ vs. $1702.9 \pm 1655.5 \mathrm{ng} / \mathrm{mL}, \mathrm{p}=0.009)$. Transthoracic echocardiography with pulmonary artery systolic pressure measurement had been performed in 189 of patients $(74.7 \%)$. Elderly cases had lower median ejection fraction values $[60(6.3 \%)$ vs. $60(5 \%), \mathrm{p}=0.001]$ together with higher right atrial diameters $(4.5 \pm$ $0.7 \mathrm{~mm}$ vs. $4.1 \pm 0.6 \mathrm{~mm}, \mathrm{p}=0.015)$ and pulmonary artery systolic pressure levels $(49.3 \pm$ $18.8 \mathrm{mmHg}$ vs. $39.4 \pm 17.8 \mathrm{mmHg}, \mathrm{p}=0.001)$ on echocardiographic examination when compared to younger counterparts. CT pulmonary angiography results were available in 194 patients $(76.7 \%)$ and they showed that the frequency of thrombi of proximal pulmonary arterial branches (main and/or lobar pulmonary arteries) was higher in elderly than in younger cases $(\mathrm{p}=0.042)$.

Increased sPESI, c-reactive protein (CRP), BUN, and creatinine levels; decreased albumin level, neutrophil-to-lymphocyte ratio, and leukocyte count as well as the presence of cough, dyspnea, pulmonary infarction, co-morbiditiy, history of immobility, malignancy, trauma, and operation were found to increase 90-day-mortality (All p values $<0.05$ ). However, multivariate analysis revealed that a sPESI equal or higher than $1(\mathrm{p}=0.034$, OR:5.25, 95\% CI:1.14-24.23), increased CRP ( $\mathrm{p}=$ 0.004, OR:1.26, 95\% CI:1.08-1.48) and BUN ( $\mathrm{p}=0.019$, OR:1.04, 95\% CI:1.01-1.07) levels, having an operation ( $\mathrm{p}=0.049$, OR:3.92, 95\% CI:0.98 - 15.62), and presence of co-morbidities ( $p=0.016$, OR:6.21, 95\% CI:1.4127.40), especially the presence of cardiopulmonary diseases $(\mathrm{p}=0.025$, OR:1.66, 95\% CI:0.34-8.15) were independent risk factors increasing mortality in elderly cases. As to younger patients, increased BUN levels ( $\mathrm{p}=0.010$, OR: 1.09, 95\% CI:1.02-1.16) and having 
pulmonary infarction $(\mathrm{p}=0.125$, OR:1.01, 95\% CI:0.53-190.1) were found as independent risk factors (Table 3). Higher D-dimer levels were not found to increase mortality risk in none of the groups.

\section{DISCUSSION}

In the current study, it was determined that the mortality rate, systolic pulmonary artery pressure, the frequency of hypoxemia, and D-dimer levels were higher in elderly patients with PE compared to younger patients. Increased BUN and CRP levels, an sPESI $\geq 1$, accompanying co-morbidities, and undergoing surgery were independent risk factors associated with increased mortality in elderly patients.

The elderly population are at increased risk for pulmonary embolism owing to both the conditions common to this age group, and the immobility which frequently accompanies them. Both reduced cardio-pulmonary reserves and increased probability of co-morbidities increase the risk of mortality in elderly patients (4). Additionally, confusion of the symptoms of cardiovascular and pulmonary diseases with the ones of PE as well as decreased ability of sensation and distinction may delay the diagnosis of PE and increase the mortality rate in elderly people(5).

PESI is one of the most widely validated prognostic model for 30-day-mortality (11). The number of parameters evaluated in simplified PESI is less than PESI and therefore it is less complicated (14). Kılıç et al. (15) showed that sPESI was an effective prognostic model to predict short- and long-term mortality PE patients regardless of age. In some other studies, the frequencies of 90-day-mortality were found 25 to $54 \%$ in elderly PE patients with a SPESI score indicating high risk $(7,16)$. In accordance with these investigations, we determined 90- 
day-mortality as high as $55 \%$ in elderly patients with a sPESI equal or greater than one. Having a sPESI $\geq 1$ was found associated with five-fold increase in 90-day-mortality rate in our elderly group, compared to the cases with an index lower than one. Given that one of the parameters scored in calculation of sPESI is being older than 80 years old and $20(19 \%)$ of cases in our elderly group were older than 80 years, this finding may not be surprising. Consistently, there was no correlation between the sPESI and 90-day-mortality in younger patients. However, as most of our elderly group are below 80 years old, some risk factors other than age may also affect mortality risk. Higher sPESI indicating increased mortality risk in elderly PE patients should make clinicians take proper measures to decrease mortality.

Co-morbidities develop with aging and those increase mortality rates in elderly people. PE results in increased frequencies of hemodynamic instability and mortality in these patients, especially, in the ones with cardiopulmonary diseases(5). A study evaluating annual mortality rates in patients with chronic obstructive pulmonary disease (COPD) have found that accompanying PE increased the mortality rate from $15 \%$ to $53.3 \%$ (17). Another study have shown raised mortality rate due to PE in cases with COPD or heart failure (18). Several other studies also reported similar increase in mortality rates in PE patients owing to various co-morbidities $(19,20)$. In consistence with previous reports, we have found that comorbidities caused increased mortality rate in elderly group and among them, this risk was more pronounced for cardiopulmonary diseases. Therefore, clinical suspicion of PE in elderly patients with cardiopulmonary diseases should prompt us to diagnose and start proper treatment in order to reduce possible mortality risk.

Having surgery increases the risk of mortality in elderly patients. Immobilization, venous stasis, and endothelial damage are the major causes of deep vein thrombosis in elderly patients undergoing surgery $(21,22)$. It has been shown that subclinical pulmonary embolism can be seen in $40-50 \%$ of elderly patients with deep vein thrombosis and it increases the risk 
of mortality (23). Hamel et al. (24) reported that PE was responsible for $47 \%$ of postoperative deaths in elderly patients. Parallel with those, mortality risk was found to be increased in our elderly PE cases being operated on within a few weeks. This finding may indicate the importance of preoperative embolism prophylaxis and necessity of careful perioperative management in elderly population.

Besides a physiological decline in renal function with aging, some co-morbid conditions such as hypertension, diabetes, and acute PE may cause renal damage in elderly people (25). Sudden increase in pulmonary artery pressure resulted from PE may cause right ventricular dysfunction and decreased cardiac output. Consequent decrement in renal blood flow results in renal dysfunction (26). Increased BUN level is an indicator of renal dysfunction. Increased BUN levels was found related with poor prognosis in liver disease and heart failure (27). One study identified a relationship indepent from creatinine levels between high BUN levels and mortality in 26,288 patients (28). Interestingly, we have determined that higher levels of BUN predicted increased mortality risk in both younger and elderly patients with PE. Given that heart failure was present in two of the younger and three of the older patients, it was thought that such increase in mortality risk did not result from heart failure accompanying to renal dysfunction. This is a novel finding in that our search did not reveal any study evaluating BUN in prediction of mortality in PE patients and this finding may indicate the importance of appropriate therapy and careful management of such PE patients in order to reduce the risk of mortality.

Recent studies have proposed that inflammatory markers and acute phase reactants may be involved in pathogenesis of venous thromboembolism and have some prognostic significance $(29,30)$. C-reactive protein was found beneficial both in diagnosis of PE and in identification of patients with higher mortality risk within first year of disease (30). CRP is reported to be associated with worse clinical outcomes and proposed as a predictor of poor 
prognosis in PE cases in another study (31). In our study, higher CRP levels has predicted increased 90-day-mortality in elderly patients, but not in younger counterparts. C-reactive protein can be a useful and easily available biochemical marker in determination of mortality risk of PE patients.

Studies evaluating the relationship between D-dimer levels and mortality risk have found contradictory results. While some studies determined increased mortality risk in PE cases with higher D-dimer levels $(4,32)$, the others did not find such a relationship (33). We did not determine any relationship between D-dimer levels and mortality risk as well.

Our study have some limitations. Since the data were retrospectively collected, one must be careful in drawing conclusions. The results of this study should be further validated by prospective randomized trials. Transthoracic echocardiography is only performed in those with more severe PE and higher probability of right ventricular dysfunction. Finally, we did not exclude patients with preexisting diseases which may also cause right ventricular enlargement (e.g. COPD).

In conclusion, the current study found quite high mortality rate in elderly pulmonary embolism patients. Higher sPESI, presence of co-morbidities and surgical procedures as well as high BUN and CRP levels are associated with increased mortality risk especially in elderly PE cases. The use of those parameters in prediction of the patients at high mortality risk may drive us to take necessary measures in order to reduce the risk of mortality.

\section{AUTHORS' NOTE}

The authors Melike Demir, Mahsuk Taylan, Hadice Selimoglu Sen, Halide Kaya, Sureyya Y1lmaz, Cengizhan Sezgi, Gulistan Karadeniz, Mehmet Guli Cetincakmak, Derya Yenibertiz, and Fusun Topcu declare that they have no conflict of interest. 
Demir et al

\section{REFERENCES}

1. Torbicki A, Perrier A, Konstantinides S, Agnelli G, Galie N, Pruszczyk P, et al. Guidelines on the diagnosis and management of acute pulmonary embolism: the Task 
Force for the Diagnosis and Management of Acute Pulmonary Embolism of the European Society of Cardiology (ESC). Eur Heart J. 2008;29(18):2276-315.

2. Stein PD, Huang H, Afzal A, Noor HA. Incidence of acute pulmonary embolism in a general hospital: relation to age, sex, and race. Chest. 1999;116(4):909-13.

3. Amin H, Mohsin S, Aslam M, Hussain S, Saeed T, Ullah MI, et al. Coagulation factors and antithrombin levels in young and elderly subjects in Pakistani population. Blood Coagul Fibrinolysis. 2012;23(8):745-50.

4. Castelli R, Bucciarelli P, Porro F, Depetri F, Cugno M. Pulmonary embolism in elderly patients: prognostic impact of the Cumulative Illness Rating Scale (CIRS) on short-term mortality. Thromb Res. 2014;134(2):326-30.

5. Krumholz HM, Wang Y, Mattera JA, Wang Y, Han LF, Ingber MJ, et al. An administrative claims model suitable for profiling hospital performance based on 30day mortality rates among patients with an acute myocardial infarction. Circulation. 2006;113(13):1683-92.

6. Darze ES, Casqueiro JB, Ciuffo LA, Santos JM, Magalhaes IR, Latado AL. Pulmonary Embolism Mortality in Brazil from 1989 to 2010: Gender and Regional Disparities. Arq Bras Cardiol. 2015.

7. Polo Friz H, Molteni M, Del Sorbo D, Pasciuti L, Crippa M, Villa G, et al. Mortality at 30 and 90 days in elderly patients with pulmonary embolism: a retrospective cohort study. Intern Emerg Med. 2015;10(4):431-6.

8. Barrett JA, Baron JA, Beach ML. Mortality and pulmonary embolism after fracture in the elderly. Osteoporos Int. 2003;14(11):889-94.

9. Cefalo P, Weinberg I, Hawkins BM, Hariharan P, Okechukwu I, Parry BA, et al. A comparison of patients diagnosed with pulmonary embolism who are $>/=65$ years with patients <65 years. Am J Cardiol. 2015;115(5):681-6. 
10. Punukollu H, Khan IA, Punukollu G, Gowda RM, Mendoza C, Sacchi TJ. Acute pulmonary embolism in elderly: clinical characteristics and outcome. Int J Cardiol. 2005;99(2):213-6.

11. Rudski LG, Lai WW, Afilalo J, Hua L, Handschumacher MD, Chandrasekaran K, et al. Guidelines for the echocardiographic assessment of the right heart in adults: a report from the American Society of Echocardiography endorsed by the European Association of Echocardiography, a registered branch of the European Society of Cardiology, and the Canadian Society of Echocardiography. J Am Soc Echocardiogr. 2010;23(7):685-713; quiz 86-8.

12. Lopez-Candales A, Dohi K, Rajagopalan N, Edelman K, Gulyasy B, Bazaz R. Defining normal variables of right ventricular size and function in pulmonary hypertension: an echocardiographic study. Postgrad Med J. 2008;84(987):40-5.

13. Qanadli SD, El Hajjam M, Vieillard-Baron A, Joseph T, Mesurolle B, Oliva VL, et al. New CT index to quantify arterial obstruction in pulmonary embolism: comparison with angiographic index and echocardiography. AJR Am J Roentgenol. 2001;176(6):1415-20.

14. Righini M, Roy PM, Meyer G, Verschuren F, Aujesky D, Le Gal G. The Simplified Pulmonary Embolism Severity Index (PESI): validation of a clinical prognostic model for pulmonary embolism. J Thromb Haemost. 2011;9(10):2115-7.

15. Kilic T, Gunen H, Gulbas G, Hacievliyagil SS, Ozer A. Prognostic role of simplified Pulmonary Embolism Severity Index and the European Society of Cardiology Prognostic Model in short- and long-term risk stratification in pulmonary embolism. Pak J Med Sci. 2014;30(6):1259-64. 
16. Dentali F, Riva N, Turato S, Grazioli S, Squizzato A, Steidl L, et al. Pulmonary embolism severity index accurately predicts long-term mortality rate in patients hospitalized for acute pulmonary embolism. J Thromb Haemost. 2013;11(12):2103-10.

17. Carson JL, Terrin ML, Duff A, Kelley MA. Pulmonary embolism and mortality in patients with COPD. Chest. 1996;110(5):1212-9.

18. Monreal M, Munoz-Torrero JF, Naraine VS, Jimenez D, Soler S, Rabunal R, et al. Pulmonary embolism in patients with chronic obstructive pulmonary disease or congestive heart failure. Am J Med. 2006;119(10):851-8.

19. Ozsu S, Oztuna F, Bulbul Y, Topbas M, Ozlu T, Kosucu P, et al. The role of risk factors in delayed diagnosis of pulmonary embolism. Am J Emerg Med. 2011;29(1):26-32.

20. Bulbul Y, Ayik S, Oztuna F, Ozlu T, Sahin S. The relationship between sociodemographic characteristics of patients and diagnostic delay in acute pulmonary thromboembolism. Ups J Med Sci. 2011;116(1):72-6.

21. Ramos A, Murillas J, Mascias C, Carretero B, Portero JL. Influence of age on clinical presentation of acute pulmonary embolism. Arch Gerontol Geriatr. 2000;30(3):189-98.

22. Weill-Engerer S, Meaume S, Lahlou A, Piette F, Saint-Jean O, Sachet A, et al. Risk factors for deep vein thrombosis in inpatients aged 65 and older: a case-control multicenter study. J Am Geriatr Soc. 2004;52(8):1299-304.

23. Taubman LB, Silverstone FA. Autopsy proven pulmonary embolism among the institutionalized elderly. J Am Geriatr Soc. 1986;34(10):752-6.

24. Hamel MB, Henderson WG, Khuri SF, Daley J. Surgical outcomes for patients aged 80 and older: morbidity and mortality from major noncardiac surgery. J Am Geriatr Soc. 2005;53(3):424-9. 
25. Aucella F, Guida CC, Lauriola V, Vergura M. How to assess renal function in the geriatric population. J Nephrol. 2010;23 Suppl 15:S46-54.

26. Angle MR, Molloy DW, Penner B, Jones D, Prewitt RM. The cardiopulmonary and renal hemodynamic effects of norepinephrine in canine pulmonary embolism. Chest. 1989;95(6):1333-7.

27. Liu X, Zhang H, Liang J. Blood urea nitrogen is elevated in patients with nonalcoholic fatty liver disease. Hepatogastroenterology. 2013;60(122):343-5.

28. Beier K, Eppanapally S, Bazick HS, Chang D, Mahadevappa K, Gibbons FK, et al. Elevation of blood urea nitrogen is predictive of long-term mortality in critically ill patients independent of "normal" creatinine. Crit Care Med. 2011;39(2):305-13.

29. Lankeit M, Kempf T, Dellas C, Cuny M, Tapken H, Peter T, et al. Growth differentiation factor-15 for prognostic assessment of patients with acute pulmonary embolism. Am J Respir Crit Care Med. 2008;177(9):1018-25.

30. Marchena Yglesias PJ, Nieto Rodriguez JA, Serrano Martinez S, Belinchon Moya O, Cortes Carmona A, Diaz de Tuesta A, et al. [Acute-phase reactants and markers of inflammation in venous thromboembolic disease: correlation with clinical and evolution parameters]. An Med Interna. 2006; 23:105-10.

31. Abul Y, Karakurt S, Ozben B, Toprak A, Celikel T. C-reactive protein in acute pulmonary embolism. J Investig Med. 2011; 59: 8-14.

32. Maestre A, Trujillo-Santos J, Visona A, Lobo JL, Grau E, Maly R, et al. D-dimer levels and 90-day outcome in patients with acute pulmonary embolism with or without cancer. Thromb Res. 2014; 133: 384-9.

33. Stein PD, Janjua M, Matta F, Alrifai A, Jaweesh F, Chughtai HL. Prognostic value of D-dimer in stable patients with pulmonary embolism. Clin Appl Thromb Hemost. 2011; 17 (6): E183-5. 
Table 1: Baseline characteristics of patients with pulmonary embolism

\section{Gender}

\section{Younger patients $(\mathbf{n} 148) \quad$ Older patients $(n=105) \quad p$} n(\%) 
Female

Male

Co-morbidities

Cardiac disease

COPD

DM

Other

\section{Clinical risk factors}

Surgery

Trauma

Malignancy

Immobilization

Symptoms at presentation

Dyspnea

Chest pain

Syncope

Hemoptysis

Cough

SPESI $\geq 1$

Venous thromboembolism

Massive embolism

Pulmonary infarction

Treatment

First-line
$86(58.1)$

68(64.8)

62(41.9)

57(38.5)

22(14.9)

11(7.4)

$6(4.0)$

$8(5.4)$
$<0.001$

32(30.5)

20(19.0)

8(7.6)

5(4.8)
$38(25.7)$

12(8.1)

$10(6.8)$

54(36.5)

117(79.1)

104(70.3)

$13(8.8)$

30(20.3)

32(21.6)

44(29.7)

64(43.2)

14(48.3)

30(20.3)
10(9.5)

$84(80.0)$

69(65.7)

$10(9.5)$

11(10.5)

29(27.6)

64(61.0)

32(30.5)

15(51.7)

0.235

0.031

0.235

90(40.2)

0.458

0.266

0.592

1.000

1.000

0.342

0.827

0.102

0.281

$<0.001$

0.056

15(51.7)

134(59.8)

Thrombolytic

14(48.3) 
Maintenance

0.132

$L M W H$

Coumadin
24(49)

124(60.8)
25(51)

$80(39.2)$

\begin{abstract}
Abbreviations: COPD: Chronic Obstructive Pulmonary Disease, DM: Diabetes Mellitus, LMWH: Low Molecular Weight Heparin, sPESI: Simplified Pulmonary Embolism Severity Index
\end{abstract}


Table 2: Comparison of laboratory parameters of the groups

\begin{tabular}{|c|c|c|c|}
\hline Laboratory Parameters & $\begin{array}{c}\text { Younger patients } \\
\text { (mean } \pm S D)\end{array}$ & $\begin{array}{c}\text { Older patients } \\
(\text { mean } \pm S D)\end{array}$ & $p$ \\
\hline \multicolumn{4}{|l|}{ Serum biochemistry } \\
\hline $\mathrm{BUN}(\mathrm{mg} / \mathrm{dL})^{\#}$ & $15.1 \pm 8.7$ & $23.3 \pm 13.3$ & $<0.001$ \\
\hline Creatinine $(\mathrm{mg} / \mathrm{dl})^{*}$ & $0.8(0.3)$ & $1(0.6)$ & 0.305 \\
\hline Albumin (g/dL) ${ }^{\#}$ & $2.9 \pm 0.6$ & $2.6 \pm 0.5$ & 0.001 \\
\hline $\mathrm{Na}(\mathrm{mEq} / \mathrm{L})^{\#}$ & $136.9 \pm 5.2$ & $137.4 \pm 4.8$ & 0.449 \\
\hline $\operatorname{CRP}(\mathrm{mg} / \mathrm{dL})^{¥}$ & $3.5(5.4)$ & $6.3(6.2)$ & 0.862 \\
\hline D-dimer $(\mathrm{ng} / \mathrm{ml})^{\#}$ & $1702.9 \pm 1655.5$ & $2331.5 \pm 1301.2$ & 0.009 \\
\hline \multicolumn{4}{|l|}{ Complete blood count } \\
\hline Leukocyte count $\left(\times 10^{3} / \mu \mathrm{L}\right)^{*}$ & $8.6(4)$ & $9.8(5.4)$ & 0.722 \\
\hline Neutrophil count $\left(\times 10^{3} / \mu \mathrm{L}\right){ }^{*}$ & $5(4.5)$ & $6.6(4.4)$ & 0.090 \\
\hline Lymphocyte count $\left(\times 10^{3} / \mu \mathrm{L}\right)^{\#}$ & $1.9 \pm 1.0$ & $1.7 \pm 0.7$ & 0.012 \\
\hline Neutrophil/lymphocyte ratio $¥$ & $2.8(2.6)$ & $5(4.2)$ & 0.510 \\
\hline Hemoglobin $(\mathrm{g} / \mathrm{dL})^{\#}$ & $12.7 \pm 8.9$ & $11.6 \pm 2.2$ & 0.228 \\
\hline Hematocrit $(\%)^{\#}$ & $38.6 \pm 7.5$ & $34.8 \pm 6.5$ & 0.320 \\
\hline Platelet count $\left(\times 10^{3} / \mu \mathrm{L}\right)^{\#}$ & $290.4 \pm 127.4$ & $271.8 \pm 106.7$ & 0.251 \\
\hline Platelet/lymphocyte ratio ${ }^{*}$ & $127.1(116.6)$ & $192.4(212.7)$ & 0.341 \\
\hline $\operatorname{MCV}(f L)^{¥}$ & $83.7(8.7)$ & $83.5(10.9)$ & 0.073 \\
\hline $\operatorname{MPV}(f L)^{\#}$ & $7.8 \pm 1.4$ & $8.2 \pm 1.5$ & 0.032 \\
\hline \multicolumn{4}{|l|}{ Arterial blood gas analysis } \\
\hline $\mathrm{pO} 2(\mathrm{~mm} \mathrm{Hg})^{\#}$ & $68.8 \pm 13.2$ & $60.5 \pm 15.3$ & 0.001 \\
\hline $\mathrm{SO} 2(\%)^{¥}$ & $94(6)$ & $86.3(9.5)$ & 0.002 \\
\hline \multicolumn{4}{|l|}{ Echocardiography } \\
\hline $\operatorname{LAD}(\mathrm{cm})^{*}$ & $3.5(0.6)$ & $3.7(0.8)$ & 0.104 \\
\hline $\operatorname{LVD}(\mathrm{cm})^{*}$ & $4.7(0.7)$ & $4.2(0.5)$ & 0.628 \\
\hline $\operatorname{RAD}(\mathrm{cm})^{\#}$ & $4.1 \pm 0.6$ & $4.5 \pm 0.7$ & 0.015 \\
\hline $\operatorname{RVD}(\mathrm{cm})^{\#}$ & $3.9 \pm 0.6$ & $4.1 \pm 0.5$ & 0.110 \\
\hline $\operatorname{EF}(\%)^{*}$ & $60(5)$ & $60(6,3)$ & 0.001 \\
\hline $\operatorname{PASP}(\mathrm{mm} \mathrm{Hg})^{\#}$ & $39.4 \pm 17.8$ & $49.3 \pm 18.8$ & 0.001 \\
\hline Localization of emboli $n(\%)$ & & & 0.042 \\
\hline Main and/or lobar pulmonary arteries & $51(45.9)$ & $51(61.4)$ & \\
\hline Segmental and/or subsegmental arteries & $60(54.1)$ & $32(38.6)$ & \\
\hline \multicolumn{4}{|c|}{$\begin{array}{l}\text { \#parameters shown as mean } \pm \text { standard deviation, } \\
{ }_{\text {p parameters shown as median(interquartile range value) }}\end{array}$} \\
\hline \multicolumn{4}{|c|}{$\begin{array}{l}\text { BUN: blood urea nitrogen, CRP: c-reactive protein, EF: ejection fraction, LAD: left atrial } \\
\text { diameter, LVD: left ventricular diameter, MCV: mean corpuscular volume, MPV: mean } \\
\text { platelet volume, PASP: pulmonary artery systolic pressure, pO2: partial oxygen pressure, } \\
\text { RAD: right atrial diameter, RVD: right ventricular diameter, sO2: oxygen saturation. }\end{array}$} \\
\hline
\end{tabular}


Table 3: Logistic regression analysis of possible prognostic factors in pulmonary embolism patients

\begin{tabular}{llll}
\hline & OR & $\mathbf{9 5} \% \mathbf{C I}$ & $\mathbf{p}$ \\
\hline Younger patients & & & \\
BUN & 1.09 & $1.020-1.160$ & 0.010 \\
Malignancy & 0.51 & $0.007-0.360$ & 0.003 \\
Pulmonary infarction & 1.01 & $0.527-190.1$ & 0.125 \\
& & & \\
Older patients & & & \\
BUN & 1.04 & $1.006-1.067$ & 0.019 \\
CRP & 1.264 & $1.080-1.481$ & 0.004 \\
SPESI & 5.25 & $1.14-24.23$ & 0.034 \\
Having operation & 3.92 & $0.979-15.623$ & 0.049 \\
Accompanying disease & 6.21 & $1.406-27.404$ & 0.016 \\
Cardiopulmonary disease & 1.66 & $0.338-8.152$ & 0.025 \\
\hline
\end{tabular}

BUN: blood urea nitrogen, CI: confidence interval, CRP: C-reactive protein, OR: odds ratio, sPESI: simplified pulmonary embolism severity index 